\title{
Significance of Initial Maternal Hemoglobin Concentration during Pregnancy in Birth Weight and Preterm Delivery in Sri Lanka
}

\author{
Athambawa Mohamed Razmy \\ Faculty of Applied Sciences, South Eastern University of Sri Lanka, Sammanthurai, Sri Lanka \\ Email: amrazmy@gmail.com, amrazmy@seu.ac.lk
}

How to cite this paper: Razmy, A.M. (2016) Significance of Initial Maternal Hemoglobin Concentration during Pregnancy in Birth Weight and Preterm Delivery in Sri Lanka. Open Access Library Journal, 3: e2725. http://dx.doi.org/10.4236/oalib.1102725

Received: October 31, 2016

Accepted: November 28, 2016

Published: December 1, 2016

Copyright $\odot 2016$ by author and Open Access Library Inc.

This work is licensed under the Creative Commons Attribution International

License (CC BY 4.0).

http://creativecommons.org/licenses/by/4.0/

\begin{abstract}
Objective: The study was conducted to investigate the influence of initial hemoglobin $(\mathrm{Hb})$ concentration of Sri Lankan pregnant mothers on baby's birth weight and preterm delivery. Methods: For this retrospective study, 3867 primigravid pregnant women in Sri Lanka were followed till they deliver the baby. Sampling method was cluster sampling where all the pregnant mothers giving singleton birth in the selected 15 health division were followed for three years. Mothers' initial $\mathrm{Hb}$ concentration, weight gain during the pregnancy and neonatal outcomes were assessed. Results: Severe iron deficiency anemia at the initial stage of pregnancy had 3.9 - 14.4 folder higher relative risk of low birth weight (LBW) and 3.0 - 8.1 folder higher relative risk of preterm delivery at $95 \%$ confidence interval. The minimum incidence of preterm delivery and maximum weight gain of mothers occurs in association with an initial $\mathrm{Hb}$ concentration of $105-125 \mathrm{~g} / \mathrm{L}$. Conclusion: The excess level of initial iron content at pregnancy does not contribute for any adverse effect on pregnancy outcome as like in the later part of pregnancy and therefore supplement of iron during the initial pregnancy for mothers can be carried out regardless of whether the mother is anemic.
\end{abstract}

\section{Subject Areas}

Public Health

\section{Keywords}

Anemia, Hemoglobin Concentration, Low Birth Weight, Preterm Delivery, Relative Risk 


\section{Introduction}

Women are more likely than men to have low iron stores because of blood loss at the time of menstruation and especially during pregnancy due to the additional maternal absorption of iron. Estimating the value of iron status in a pregnant women is practically problematic because during pregnancy $\mathrm{Hb}$ concentration decreases due to the expansion of plasma volume. Therefore the $\mathrm{Hb}$ concentration measurement taken at the beginning of pregnancy could be a good measure than the measurement taken in the final stage to express the status of the mothers' iron content. When the Hb concentration of the pregnant mother is below $110 \mathrm{~g} / \mathrm{L}$, it is said to be anemic mother [1] and when the $\mathrm{Hb}$ concentration is below $80 \mathrm{~g} / \mathrm{L}$, it is said to be severe anemia [2]. Anemia in pregnant women continues to be a major health problem in many developing countries such as Sri Lanka and more than half of the pregnant women in the world have $\mathrm{Hb}$ concentration levels indicative of anemia [3]. Anemia diagnosed early in pregnancy is associated with increased risks of LBW and preterm delivery whereas in some studies the association between anemia and outcomes is in reversed direction especially at the last stage of pregnancy [4] [5] [6]. LBW is defined as a birth weight less than $2500 \mathrm{~g}$; the measurement being taken preferably within the first hour of life, before significant weight loss has occurred and preterm delivery is defined as childbirth occurring at less than 37 completed weeks of gestation [7]. LBW and preterm delivery are closely associated with foetal and neonatal mortality and morbidity, inhibited growth and cognitive development and chronic diseases later in life [8] [9].

Failure to supply enough iron to produce excess plasma during the pregnancy will result anemia in mothers. The provision of iron supplements to pregnant women throughout the pregnancy period is one of the most widely practiced public health measures in Sri Lanka. However the supplementation of routine iron during pregnancy, regardless of whether the mother is anemic, has been debated extensively. Surprisingly little is known about the benefits of supplemental iron for the mother or her offspring during fetal or postnatal life [10]. Murphy et al. studied the relation of $\mathrm{Hb}$ concentration in first and second trimesters to outcome of pregnancy and found a U-shaped relationship between maternal $\mathrm{Hb}$ concentrations and birth weight [11]. Several other studies also witnessed the increased prevalence of LBW in anemic women [12] [13] [14]. On the other hand, epidemiologic studies had found an association between high maternal $\mathrm{Hb}$ concentrations and an increased prevalence of LBW [15]. The reason could be that the very high $\mathrm{Hb}$ concentrations usually indicate poor high blood viscosity, which restricts the uterus movement that is also a risk for LBW [16] [17]. A study on maternal $\mathrm{Hb}$ concentration and birth weight showed that the minimum incidence of LBW and preterm delivery occurs in association with an $\mathrm{Hb}$ concentration of $95-105$ g/L. Severe anemia was associated with both LBW babies and preterm delivery. $\mathrm{Hb}$ concentrations more than $120 \mathrm{~g} / \mathrm{L}$ at the last stage of pregnancy were associated with a more than 3-fold increased risk of preeclampsia and LBW [2]. A study conducted on the relationship between maternal $\mathrm{Hb}$ concentration and birth weight in different ethnic groups found that the lowest incidence of LBW and preterm delivery occurred with 
an Hb level of $95-105 \mathrm{~g} / \mathrm{L}$ for all ethnic groups studied but the prevalence of LBW differs among the ethnic groups [18]. In India it was shown that the relative risk of LBW is 1.53 for mothers having initial $\mathrm{Hb}$ level less than $90 \mathrm{~g} / \mathrm{L}$ [19]. Some studies reported a positive association between maternal serum ferritin and preterm delivery [20] [21] [22]. Substantial amount of evidence shows that maternal iron deficiency anemia early in pregnancy can result in LBW subsequent to preterm birth. In Welsh, women who were first diagnosed with anemia $(\mathrm{Hb}$ level $<104 \mathrm{~g} / \mathrm{L})$ at initial pregnancy had a 1.18 1.75 -fold higher relative risk of preterm birth, low birth weight, and prenatal mortality [23]. Three times of higher risk of preterm delivery were observed for low income group young black women in the United States who were with anemia [24]. Another study in rural Nepal women reveled that iron deficiency with anemia in the first or second trimester was associated with a 1.87 fold higher risk of preterm birth [25]. In this study, 3867 pregnant women in Sri Lanka were followed to find the significance of initial maternal hemoglobin concentration during pregnancy in birth weight and preterm delivery. Furthermore, this study examines and compares the published information on the effects of iron deficiency on pregnancy outcome with the Sri Lankan information.

\section{Materials and Methods}

For this retrospective study, 3867 primigravid pregnant women in Sri Lanka were followed. An ethical approval for this study was obtained from the institutes of the author and consent of the pregnant mothers was obtained before recording the information. Sampling method was cluster sampling where all the pregnant mothers giving singleton birth in the selected 15 health division in Sri Lanka were considered. This study was conducted for three years and the information of 369 mothers misshaped during this period. The $\mathrm{Hb}$ test was used to measure the initial $\mathrm{Hb}$ level at pregnancy for each mother along with complete blood count. The pregnancy outcomes were recorded at delivery. Models were used to derive estimates and their 95\% prediction intervals of birth weight, weight gain of mothers during pregnancy, prevalence of LBW and incidence of preterm delivery. Any delivery occurred before 37 weeks of gestation was considered preterm delivery and the birth weight of less than $2500 \mathrm{~g}$ was considered as LBW. The associations of initial $\mathrm{Hb}$ concentration with LBW and preterm delivery were analyzed. The relative risks were estimated using linear logistic models after log it transformations of the proportions and for interpretation the estimations were backtransformed to the original scale.

\section{Results}

Among the 3498 mothers observed, $1.1 \%$ of the mothers were in severe anemic condition with initial maternal $\mathrm{Hb}$ concentration less than $80 \mathrm{~g} / \mathrm{L}$. 16\% were anemic with initial maternal $\mathrm{Hb}$ concentration $80-104 \mathrm{~g} / \mathrm{L}$ and $73.4 \%$ were in the normal category with initial maternal $\mathrm{Hb}$ concentration $105-125 \mathrm{~g} / \mathrm{L}$. The rest 9.6\% were with excess initial maternal $\mathrm{Hb}$ concentration with more than $125 \mathrm{~g} / \mathrm{L}$. The average birth weight observed was $2971.5 \pm 15.3 \mathrm{~g}$ at $95 \%$ confidence level with $12.1 \% \pm 1.0 \%$ prevalence of 
LBW. The average baby's birth weights for mothers with different categories of initial maternal $\mathrm{Hb}$ concentrations are given in Figure 1. The average birth weight of $2454.7 \mathrm{~g}$ was observed for the mothers with initial maternal $\mathrm{Hb}$ concentration less than $80 \mathrm{~g} / \mathrm{L}$, which was $522.3 \mathrm{~g}$ significantly less compare to the average birth weight given by the rests of the mothers whose initial maternal $\mathrm{Hb}$ concentration was $\geq 80 \mathrm{~g} / \mathrm{L}(\mathrm{P}<0.001)$. For the mothers whose initial maternal $\mathrm{Hb}$ concentration was $\geq 80 \mathrm{~g} / \mathrm{L}$, a mild increase of birth weight was observed with increasing initial maternal $\mathrm{Hb}$ concentration but this increase was not statistically significant $(P=0.10)$. This result does not agree with $\mathrm{U}$ shaped relationship found between birth weight and initial maternal $\mathrm{Hb}$ concentration reported by Murphy et al. [11]. This U shaped relationship might have arisen at the latter part of the pregnancy with second or third trimester maternal $\mathrm{Hb}$ concentration and therefore one no need to worry about taking excess iron supplement at the beginning of the pregnancy.

Figure 2 shows the prevalence of LBW for mothers with different categories of initial $\mathrm{Hb}$ concentration. The linear logistic models fitted using probit procedure in SAS to compare the relative risk of giving LBW for severe anemic mothers (initial Hb concatration $<80 \mathrm{~g} / \mathrm{L}$ ) with normal mothers ( $\mathrm{Hb}$ concentration $105-125 \mathrm{~g} / \mathrm{L}$ ) yielded the odds ratio $\left(\hat{\Psi}_{12}=\frac{\hat{p}_{1} /\left(1-\hat{p}_{1}\right)}{\hat{p}_{2} /\left(1-\hat{p}_{2}\right)}\right)$ of $\mathrm{e}^{2.0106}$ with standard error of 0.34 . This implies with 95\% certainty that the relative risk of LBW for mothers with severe anemic compared to normal mother is between 3.9 and 14.4. The relative risk of giving LBW for the anemic mothers with normal mothers is 1.4. This result agrees with ratio obtained for the Walsh women studied by Murphy et al. [23]. No difference in risk of giving LBW was found between mothers with normal and excess (>125 g/L) level of initial maternal $\mathrm{Hb}$ concentration.

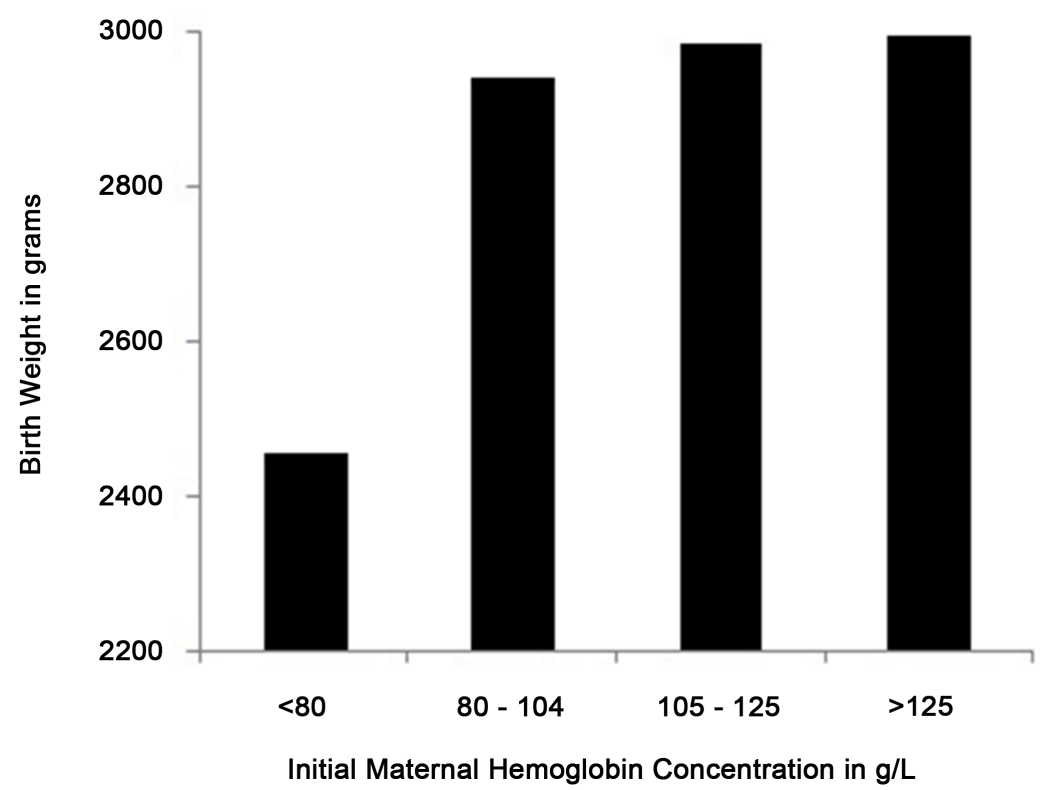

Figure 1. Mothers' initial $\mathrm{Hb}$ concentration and birth weight. 


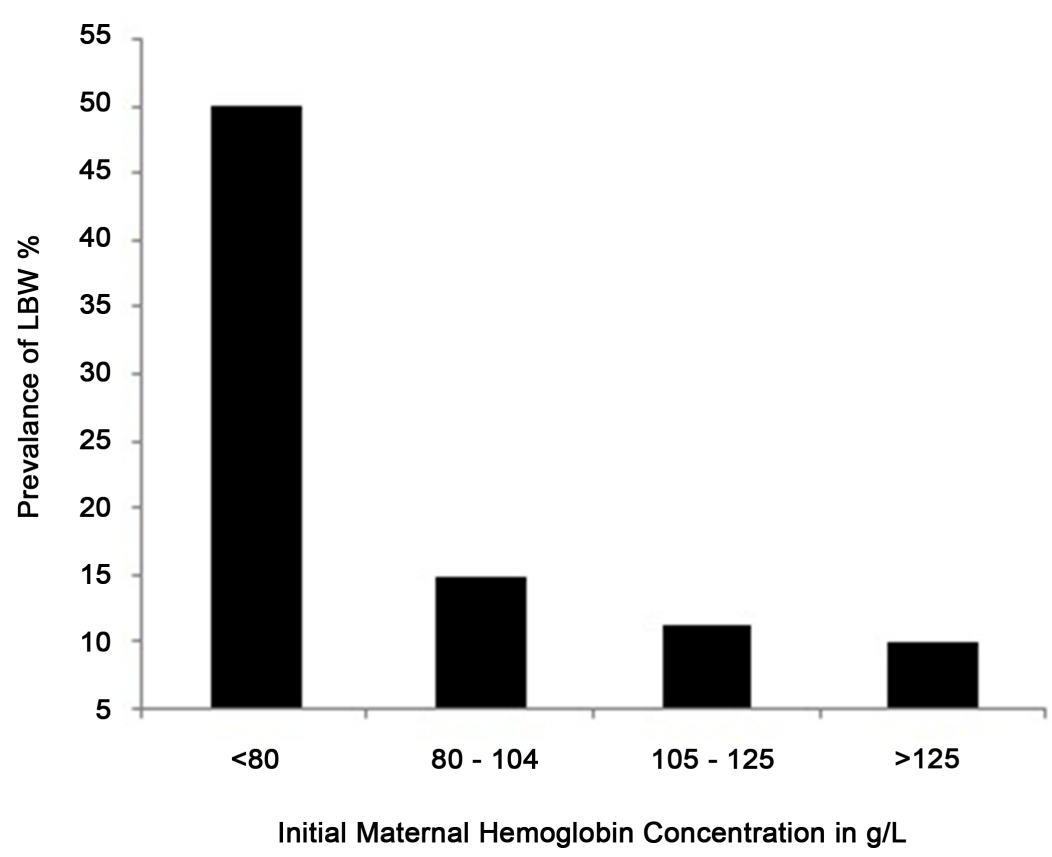

Figure 2. Mothers' initial Hb concentration and prevalence of LBW.

Figure 3 shows the weight gain observed for mothers with different categories of initial $\mathrm{Hb}$ concentration. The average weight gain of mothers during pregnancy was $9.29 \pm$ $0.15 \mathrm{Kg}$ at $95 \%$ confidence level. Mothers with severe anemic had significantly very less weight gain of $6.30 \mathrm{Kg}$ compare to mothers in the other initial maternal $\mathrm{Hb}$ concentration category $(P<0.001)$. Even though the weight gain of the mothers with normal initial $\mathrm{Hb}$ concentration was greater than the anemic and excess initial $\mathrm{Hb}$ concentration mothers, these differences were not statistically significant $(P=0.176)$.

Figure 4 shows the incidence of preterm delivery for different initial $\mathrm{Hb}$ concentration mothers. Incidence of preterm delivery was $10.9 \% \pm 1.0 \%$ at $95 \%$ confidence level which is very close to the incidence level reported for the South East Asia which is $11.1 \%$ (7). Mothers who were initially diagnosed with severe anemia had a $3.0-8.1$ fold higher relative risk of preterm delivery compare to the mothers with normal initial $\mathrm{Hb}$ concentration. Even though higher incidence of preterm delivery was observed for the anemic (12.5\%) and excess initial $\mathrm{Hb}$ concentration (10.4\%) mothers, compare to normal initial $\mathrm{Hb}$ concentration mothers (10.2\%), the risk was not significantly high $(P=$ $0.148)$.

\section{Discussion}

This study provides substantial evidence that severe maternal initial iron deficiency $(<80 \mathrm{~g} / \mathrm{L})$ results significantly very less weight gain of mothers during the pregnancy, increases the risk of preterm delivery and subsequent low birth weight. Excess initial maternal $\mathrm{Hb}$ concentration $(>125 \mathrm{~g} / \mathrm{L})$ does not cause any adverse effects in terms of mothers weight gain during the pregnancy, LBW and preterm delivery. In overall, the best initial maternal $\mathrm{Hb}$ concentration could be 105 to $125 \mathrm{~g} / \mathrm{L}$ which is not tally with 


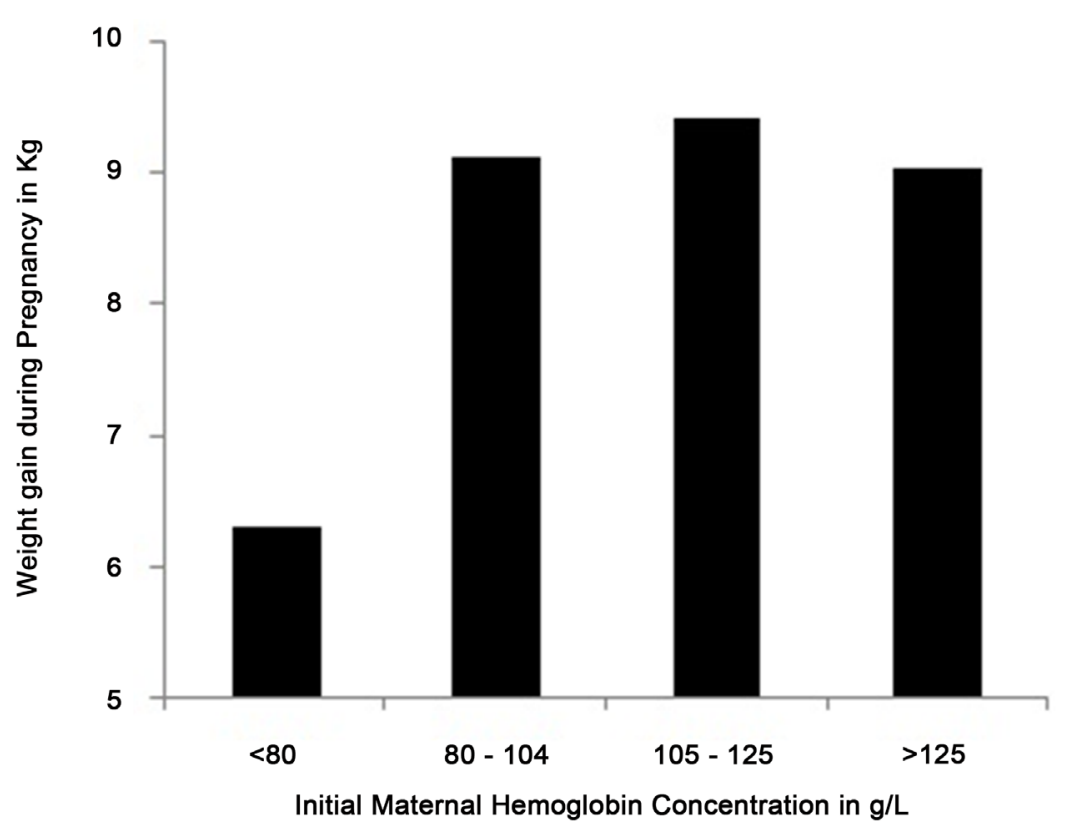

Figure 3. Mothers' initial $\mathrm{Hb}$ concentration and weight gain observed during the pregnancy.

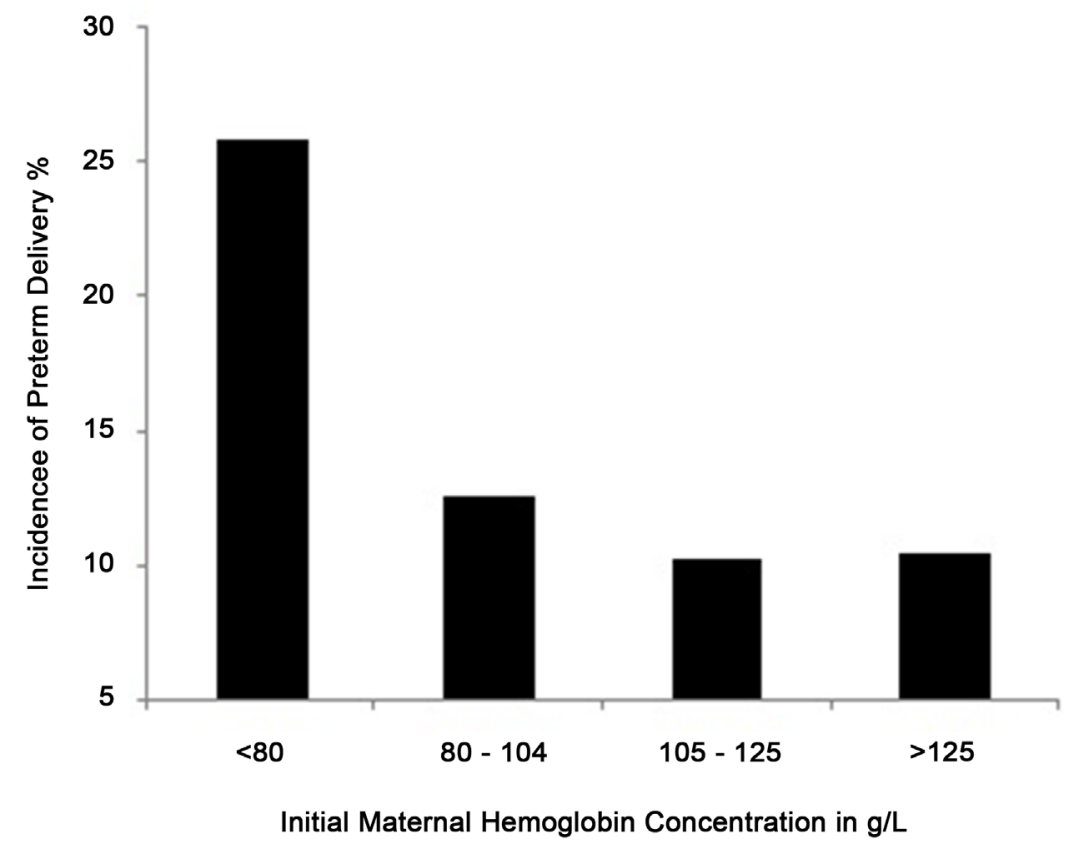

Figure 4. Mothers' initial $\mathrm{Hb}$ concentration and incidence of preterm delivery.

the study of Steer (2000) that the minimum incidence of LBW and preterm delivery occurs in association with an $\mathrm{Hb}$ concentration of $95-105 \mathrm{~g} / \mathrm{L}$.

\section{Conclusion}

This study reveals that the excess iron during initial pregnancy does not cause any 
harmful effect in the pregnancy outcome; therefore, the practice of routine iron supplementation during the initial pregnancy can be continued in Sri Lanka. In this study, the iron intake of women during the pregnancy was not considered and this factor should be included in future studies.

\section{Acknowledgements}

This work was supported by the Research and Publication Committee of the South Eastern University of Sri Lanka [SEUSL/RPC/FAS/A-71] and the Higher Education for the Twenty First Century Project, Sri Lanka [SEUSL/O-AS/N1].

\section{References}

[1] World Health Organization (2013) The Prevalence of Anaemia in Women: A Tabulation of Available Information WHO/MCH/MSM/92.2. 2nd Edition.

[2] Steer, P. (2000) Maternal Hemoglobin Concentration and Birth Weight. American Journal of Clinical Nutrition, 71, 1285S-1287S.

[3] Cyril, C.D. (2007) The Prevalence of Anemia among Pregnant Women at Booking in Enugu, South Eastern Nigeria. Medscape General Medicine, 9, 11.

[4] Scholl, T.O. and Hediger, M.L. (1994) Anemia and Iron-Deficiency Anemia: Compilation of Data on Pregnancy Outcome. American Journal of Clinical Nutrition, 59, 492S-500S.

[5] Mahomed, K. (2000) Iron and Folate Supplementation in Pregnancy. Cochrane Database of Systematic Reviews, 2000, CD001135.

[6] Nyuke, R.B. and Letsky, E.A. (2000) Etiology of Anemia in Pregnancy in South Malawi. American Journal of Clinical Nutrition, 72, 247-256.

[7] World Health Organization (2012) International Classification of Diseases and Related Health Problems. 10th Revision.

[8] Huddy, C.L., Johnson, A. and Hope, P.L. (2001) Educational and Behavioral Problems in Babies of 32 - 35 Weeks Gestation. Archives of Disease in Childhood. Fetal and Neonatal Edition, 85, 23-28. https://doi.org/10.1136/fn.85.1.F23

[9] Wang, M.L., Dorer, D.J., Fleming, M.P. and Catlin, E.A. (2004) Clinical Outcomes of NearTerm Infants. Pediatrics, 114, 372-376. https://doi.org/10.1542/peds.114.2.372

[10] Lindsay, H.A. (2000) Anemia and Iron Deficiency: Effects on Pregnancy Outcome. American Journal of Clinical Nutrition, 71, 1280-1284.

[11] Murphy, J.F., O’Riordan, J., Newcombe, R.J., Coles, E.C. and Pearson, J.F. (1986) Relation of Hemoglobin Levels in First and Second Trimesters to Outcome of Pregnancy. Lancet, 1, 992-995. https://doi.org/10.1016/S0140-6736(86)91269-9

[12] Hemminki, E. and Rimpela, U. (1991) Iron Supplementation, Maternal Packed Cell Volume, and Fetal Growth. Archives of Disease in Childhood, 66, 422-425. https://doi.org/10.1136/adc.66.4_Spec_No.422

[13] Agarwal, K.N., Agarwal, D.K. and Mishra, K.P. (1991) Impact of Anemia Prophylaxis in Pregnancy on Maternal Hemoglobin, Serum Ferritin and Birth Weight. Indian Journal of Medical Research, 94, 277-280.

[14] Singla, P.N., Tyagi, M., Kumar, A., Dash, D. and Shankar, R. (1997) Fetal Growth in Maternal Anemia. Journal of Tropical Pediatrics, 43, 89-92. https://doi.org/10.1093/tropej/43.2.89

[15] Yip, R. (2000) Significance of an Abnormally Low or High Hemoglobin Concentration 
during Pregnancy: Special Consideration of Iron Nutrition. American Journal of Clinical Nutrition, 72, 272-279.

[16] Steer, P.J. (2000) Maternal Hemoglobin Concentration and Birth Weight. American Journal of Clinical Nutrition, 71, 1285S-1287S.

[17] Garn, S.M., Ridella, S.A., Tetzold, A.S. and Falkner, F. (1981) Maternal Hematological Levels and Pregnancy Outcomes. Seminars in Perinatology, 5, 155-162.

[18] Steer, P., Alam, M.A., Wadsworth, J. and Welch, A. (1995) Relation between Maternal Haemoglobin Concentration and Birth Weight in Different Ethnic Groups. BMJ, 310, 489491. https://doi.org/10.1136/bmj.310.6978.489

[19] Hirve, S.S. and Ganatra, B.R. (1994) Determinants of Low Birth Weight: A Community Based Prospective Cohort Study. Indian Pediatrics, 10, 1221-1225.

[20] Goldenberg, R.L., Tamura, T., DuBard, M., Johnston, K.E., Copper, R.L. and Neggers, Y. (1996) Plasma Ferritin and Pregnancy Outcome. American Journal of Obstetrics and Gynecology, 175, 1356-1359. https://doi.org/10.1016/S0002-9378(96)70054-6

[21] Tamura, T., Goldenberg, R.L., Johnston, K.E., Cliver, S.P. and Hickey, C.A. (1996) Serum Ferritin: A Predictor of Early Spontaneous Preterm Delivery. Obstetrics \& Gynecolog, 87, 360-365. https://doi.org/10.1016/0029-7844(95)00437-8

[22] Rondo, P.H., Abbott, R., Rodrigues, L.C. and Tomkins, A.M. (1997) The Influence of Maternal Nutritional Factors on Intrauterine Growth Retardation in Brazil. Paediatric and Perinatal Epidemiology, 11, 152-166. https://doi.org/10.1046/j.1365-3016.1997.d01-16.x

[23] Murphy, J.F., O’Riordan, J., Newcombe, R.J., Coles, E.C. and Pearson, J.F. (1986) Relation of Hemoglobin Levels in First and Second Trimesters to Outcome of Pregnancy. Lancet, 1, 992-995. https://doi.org/10.1016/S0140-6736(86)91269-9

[24] Scholl, T.O., Hediger, M.L., Fischer, R.L. and Shearer, J.W. (1992) Anemia vs Iron Deficiency: Increased Risk of Preterm Delivery in a Prospective Study. American Journal of Clinical Nutrition, 55, 985-988.

[25] Hemminki, E. and Starfield, B. (1978) Routine Administration of Iron and Vitamins during Pregnancy: Review of Controlled Clinical Trials. British Journal of Obstetrics and Gynaecology, 85, 404-410. https://doi.org/10.1111/j.1471-0528.1978.tb14905.x

Submit or recommend next manuscript to OALib Journal and we will provide best service for you:

- Publication frequency: Monthly

- 9 subject areas of science, technology and medicine

- Fair and rigorous peer-review system

- Fast publication process

- Article promotion in various social networking sites (LinkedIn, Facebook, Twitter, etc.)

- Maximum dissemination of your research work

Submit Your Paper Online: Click Here to Submit

Or Contact service@oalib.com 